\title{
SOBRE TEMPOS E ESPAÇOS DA ESCOLA: DO PRINCÍPIO DO CONHECIMENTO AO PRINCÍPIO DA SOCIALIDADE
}

\author{
Marília Gouvea de Miranda*
}

\begin{abstract}
RESUMO: Este artigo discute as propostas de organização do ensino em ciclos de formação, buscando apreender os pressupostos subjacentes à racionalidade das reformas educacionais em curso no Brasil. Entende que essas propostas implicam uma mudança dos princípios que regem a organização dos espaços e tempos da escola pública: a escola constituída no princípio do conhecimento estaria dando lugar a uma escola orientada pelo princípio da socialidade. Trata-se de uma mudança na maneira de conceber a escola, com importantes implicaçóes para a relação educação e sociedade. É abordada a diversidade de significados atribuídos à idéia de ciclos por parte dessa literatura, bem como a ausência de uma discussão clara sobre seus fundamentos. Conclui que essa inovação deva ser mais debatida, uma vez que se constata que a maior parte das publicaçôes sobre o tema está orientada para a sua justificação.
\end{abstract}

Palavras-chave: Ciclos de formação. Reforma educacional. Racionalidade. Política educacional.

ABOUT THE TIME AND THE SPACE OF THE SCHOOL:

FROM THE PRINCIPLE OF KNOWLEDGE TO THE PRINCIPLE OF SOCIABLENESS

ABSTRACT: This article discusses the proposals of the education organization in terms of formation cycles. Its aim is to understand the underlying principles related to the rationality of the educational reforms in course in Brazil. It understands that these proposals imply a change in the principles that conduct the organization of the spaces and times of the public school: the school built on the principle of the knowledge would be giving place to a school guided on the principle

* Doutora em educação pela Pontifícia Universidade Católica de São Paulo (PUC-SP) e professora da Universidade Federal de Goiás (UFG) e da Universidade Católica de Goiás (UCG). E-mail:marilia.miranda@uol.com.br

Educ. Soc., Campinas, vol. 26, n. 91, p. 639-651, Maio/Ago. 2005 
Sobre tempos e espaços da escola: do princípio do conhecimento...

of the sociableness. It deals with a change in the way of conceiving the school with important implications in the relationship between education and society. The diversity of meanings attributed to the idea of cycles as stated in this literature is questioned, as well as the absence of a clear explanation about its principles. It concludes that this innovation must be more debated since most of publications on the subject are guided by its justification.

Key words: Formation cycles. Educational reform. Rationality. Educational politics.

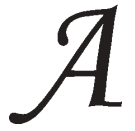

retórica em defesa de reformas na educação, que vai muito além dos documentos oficiais, quer transformar coraçōes e mentes. O âmago das reformas não está nas mudanças objetivas, formais e técnicas das políticas públicas, mas na consolidação de uma racionalidade que deverá orientar a educação de massas no mundo ocidental globalizado. Justifica-se, assim, um grande esforço de "concertación" mediante o qual se deve aderir a uma nova concepção de educação. Está em causa, portanto, uma mudança na educação de massas que, se não chega a ser nova em seus fundamentos, aparece aos olhos de muitos como absolutamente inovadora, atual e necessária.

A organização do ensino em ciclos de formação ou ciclos de aprendizagem é exemplar do ponto de vista dessa discussão. Vários municípios e estados brasileiros vêm adotando esse modelo de organização escolar em sua rede de ensino e não têm sido poucos os esforços empreendidos para promover a adesão - de professores, pais, alunos e de outros educadores - a uma inovação dessa magnitude. Afinal, trata-se de uma proposta que modifica não só a organização escolar, mas a compreensão de educação em seu significado social mais amplo. Essa importante mudança no modo de conceber a educação pública, que define o destino de toda uma geração de crianças e adolescentes, ainda não foi suficientemente discutida, uma vez que os estudos publicados sobre essa questão no Brasil são, em sua quase totalidade, vinculados à justificação e fundamentação das propostas em curso.

Ao tomar a questão das políticas públicas voltadas para a organização do ensino por ciclos de formação, pretende-se, neste artigo, apreender os pressupostos subjacentes à racionalidade do pensamento reformista na educação contemporânea. Busca-se, particularmente, pôr em causa a mudança que vem se verificando na organização dos espa- 
ços e dos tempos da escola pública: a escola constituída sob o princípio do conhecimento estaria dando lugar a uma escola orientada pelo princípio da socialidade. O termo "socialidade" está sendo adotado aqui para ressaltar que a escola organizada em ciclos se situa como um tempo/ espaço destinado à convivência dos alunos, à experiência de socialidade, distinguindo-se dos conceitos de socialização e de desenvolvimento da sociabilidade tratados pela sociologia e pela psicologia.

Vista de uma perspectiva liberal clássica, a escola é uma instância socializadora que tem a incumbência de preparar as novas geraçóes para a vida social. Isso se daria mediante um processo pelo qual as novas gerações entram em contato com a tradição, com valores e saberes do mundo que as recebe, para, a partir daí, imprimirem suas próprias referências, que poderão ser mais adaptativas e conservadoras ou mais independentes e autônomas. Essa escola foi orientada para o ensino, sustentando-se em uma didática sobre a arte de tudo ensinar a todos, atenta às necessidades e vicissitudes psicológicas de um aluno que desponta como indivíduo em uma sociedade que disfarça mal, sob o manto da igualdade de direitos, sua realidade injusta e excludente.

Essa concepção de escola nunca chegou a se efetivar plenamente porque suas promessas de inclusão social sempre foram uma impossibilidade para as classes trabalhadoras e mesmo os filhos das elites não tiveram como escapar de uma escolarização que jamais deixou de reproduzir internamente as contradições do mundo burguês, sendo obrigada a conviver com a violência, com a desigualdade e com a injustiça. É, assim, impossível pensar essa escola dissociada das contradições históricas nas quais ela se constituiu e se consolidou.

A sucessão de reformas efetivadas no século XX nada mais foi que uma seqüência de tentativas malogradas de explicar e solucionar os problemas da escola moderna, que passa a ser identificada por seus detratores como "tradicional". Novos modelos, propostas, teorias, justificações apresentam-se e vão, pouco a pouco, consolidando uma mudança no modo de conceber a escola e fortalecendo o rechaço a tudo que se apresenta como "tradicional", o que, afinal, não é uma peculiaridade da educação, mas uma característica da cultura do século XX: o repúdio à tradição (Arendt, 1979; Adorno, 1995).

O princípio que vem orientando toda a concepção e a organização escolar seriada é o conhecimento, porque o que reúne os alunos e 
Sobre tempos e espaços da escola: do princípio do conhecimento...

configura a dinâmica do processo ensino-aprendizagem é a aquisição de determinados conhecimentos e processos mediados pelos professores. A organização escolar é, assim, definida pelo pertencimento a uma determinada série fixada arbitrariamente como anual, na qual são agrupados os alunos que já sabem e os que ainda não sabem determinados conteúdos. Os que não logram essa aprendizagem são retidos, passando a conviver com outro grupo de alunos com aquisições e dificuldades que, em tese, seriam mais parecidas com as suas, ainda que em defasagem cronológica. Há uma preocupação com o desenvolvimento social do aluno, mas esse desenvolvimento é subordinado ou decorrente do processo de ensino e aprendizagem. Como já tem sido muito discutido, os mecanismos de reprovação podem gerar graves danos à auto-estima do aluno, promover a discriminação e a exclusão definitiva do aluno do processo de escolarização.

O princípio que se sustenta na organização escolar em ciclos de formação contrapõe-se frontalmente ao anterior e acarreta profundas alteraçôes. Defende que os alunos sejam agrupados em ciclos e que o critério de inclusão se deva operar por faixa etária ou por etapa de desenvolvimento humano. Para assegurar que os alunos permaneçam na escola, deverá evitar-se que sejam retidos por exigências externas que se interponham ao seu desenvolvimento, como ocorre nas escolas submetidas ao critério do conhecimento.

Assim, o cerne da argumentação em defesa da organização escolar em ciclos (de aprendizagem, de formação ou de desenvolvimento) é uma mudança radical no conceito de reprovação. A sustentação dessa reforma advém da necessidade de se fazer com que os alunos não mais sejam excluídos da educação formal, o que se daria mediante a retirada dos mecanismos de aprovação/promoção ou reprovação/retenção/exclusão.

Isso implica mudar o conceito de escola ou, o que dá no mesmo, a noção de socialização mediada pela escola, que deixa de ser orientada por um critério, digamos iluminista, de que a emancipação dos indivíduos deva ocorrer mediante a aquisição de conhecimentos, saberes, técnicas e valores que lhes permitam viver em uma sociedade mediada por esses conhecimentos, saberes, técnicas e valores, passando a orientarem-se por uma noção de socialidade que prescinde da mediação do conhecimento como sua dimensão fundamental, sendo a socialidade per si o seu critério. O importante é que os alunos permaneçam na escola, dis- 
ponham de tempo e de espaço para que possam desfrutar o que ela possa lhes oferecer, inclusive a oportunidade de adquirir conhecimentos, mas não apenas isso ou não fundamentalmente isso: que eles possam viver ali e agora uma experiência de cidadania, de convivência, de formação de valores sociais.

A proposta de organização por ciclos seria, assim, uma mudança no modo de conceber o processo de avaliação escolar que se realizaria mediante uma profunda alteração no conceito de tempo e de espaço na escola. Se um ciclo é, segundo nos diz o Dicionário Aurélio, uma "série de fenômenos que se repetem numa ordem determinada", está sendo proposto que seja dado mais tempo para que, durante a permanência naquele espaço, os alunos possam se beneficiar mais da escola, que sejam completados seus "ciclos", que os círculos se fechem.

Se a seqüência dos anos que se sucedem no regime seriado aparece como uma cronologia estéril e arbitrária, a idéia de ciclos contém um misterioso sentido que sugere um certo naturalismo teleológico: círculos que se fecham, processos que naturalmente se completariam, etapas que se cumprem seguindo uma finalidade que lhes seria inerente. A racionalidade que sustenta a idéia de ciclos não é, portanto, clara. Ciclos de quê? De aprendizagem, de formação, de desenvolvimento? O que faz girar o ciclo? Seria com base em um critério antropológico, como etapas naturais do desenvolvimento humano que se cumprem? Ou seria um critério psicológico de desenvolvimento, de disposições etárias para a aprendizagem? Ou seria um princípio ético?

As respostas a estas questões variam muito de autor para autor. Perrenoud (2004, p. 35) propõe uma "definição mínima": "Um ciclo de aprendizagem é um ciclo de estudos no qual não há mais reprovação". Já Andréa Krug (2002, p. 17), referindo-se à reforma da Secretaria Municipal de Educação de Porto Alegre, lembra que os "ciclos de formação" são organizados segundo as "fases de formação: infância (6 a 8 anos); pré-adolescência (9 a 11 anos) e adolescência (12 a 14 anos)". A respeito de um trecho da proposta em que se caracteriza o primeiro ciclo como uma transição do estágio pré-operacional para operatório concreto, numa concepção inspirada em Piaget, ela adverte que não se deve entender que essas caracterizações cognitivas se dêem naturalmente, pois são construídas a partir de atividades pedagógicas diferenciadas proporcionadas pela escola. Ressaltando o conceito de Vigotski (1996) 
Sobre tempos e espaços da escola: do princípio do conhecimento...

relativo às "idades-crise" (pós-natal, 1 ano, 3 anos, 7 anos, 13 anos e 17 anos), ela considera que existe um "desenvolvimento possível a cada fase da formação" da criança e do adolescente. Lembra ainda Wallon e seu famoso plano de reforma da educação francesa após a Segunda Guerra Mundial, elaborado em 1946-1947 (Plano Langevin-Wallon, 2000), que teria sido precursor da escola em ciclos de formação humana ao prever a organização do ensino em três ciclos: o primeiro deles refere-se às crianças de 3 a 11 anos (incluindo a escola maternal), sendo fixada a obrigatoriedade a partir de 6 anos; o segundo destinado às crianças de 11 a 15 anos e o terceiro, de 15 a 18 anos. Também Elvira Souza Lima, fundamentada em Vigotski e Wallon, retoma a proposta deste último, lembrando que o princípio organizativo dos ciclos orientava-se:

pelas características do desenvolvimento humano, respeitando cada período de formação sem antecipar formas de atividade e aquisições e sem forçar o educando a trabalhar com o conhecimento de formas inadequadas, ou por serem precoces (...) ou por terem já sido ultrapassadas no processo de desenvolvimento do aluno (...). Lima, 2002, p. 13)

Miguel Arroyo (1999, p. 158), em uma visão menos ancorada na psicologia, também situa sua noção de ciclos nas "temporalidades do desenvolvimento humano", na "especificidade de seus tempos - ciclos": "As idades da vida, da formação humana passam a ser o eixo estruturante do pensar, planejar, intervir e fazer educativos, da organização das atividades, dos conhecimentos, dos valores, dos tempos e espaços”. Ainda que os fundamentos dessa concepção antropológica de desenvolvimento humano não restem claros, na proposta implementada pela Prefeitura $\mathrm{Mu}$ nicipal de Belo Horizonte, a Escola Plural, os ciclos foram assim organizados: $1^{\circ}$ ciclo (infância), para alunos de 6 a 9 anos de idade; $2^{\circ}$. ciclo (pré-adolescência), de 9 a 12 anos; $3^{\circ}$. ciclo (adolescência), 12 a 14 anos.

Mais cauteloso, Luiz Carlos de Freitas (2003) afirma "não rejeitar" essa concepção de ciclo com base nas "fases de desenvolvimento das crianças" mas busca expandi-la, "adicionando um outro modo de conceber a dinâmica da formação do aluno e que contrarie tanto a lógica da exclusão como da submissão" (p. 55). Fundamentando-se no pedagogo russo Pistrak (autor também muito citado por Krug, 2002), Freitas lembra que, para além do lado psicológico do desenvolvimento, há também "o lado social da formação". 
Seria engraçado negar, é claro, que nas diferentes idades a criança reage de formas diferentes aos fenômenos externos, compreende diferentemente. Evidentemente, cada idade tem suas peculiaridades, devemos levá-las em conta, e muito seriamente, na escola. Mas da incontestabilidade dessas características gerais da criança à predefinição dos interesses da criança pela sua idade há uma grande distância. Essas características gerais do cérebro da criança são apenas a forma na qual se fundem os interesses da criança, preenchida pela vida externa, pela vida do ambiente social da criança, a forma na qual entra um conteúdo determinado. Esse conteúdo, em nenhum grau, depende das características fisiológicas do cérebro em desenvolvimento: ele, por inteiro, é o reflexo de fenômenos externos da vida. (Pistrak, 1924, apud Freitas, 2003, p. 57-58)

Os ciclos não devem ser, portanto, uma mera "solução pedagógica”, pois seriam compreendidos como instrumentos de desenvolvimento de novas relações sociais que viriam se contrapor às relações vigentes, como "instrumentos de resistência":

os tempos e espaços da escola são colocados a serviço de novas relações de poder entre o estudante e o professor, com a tarefa de formar para a vida, na atualidade, propiciando o desenvolvimento de novas relações entre as pessoas e entre as pessoas e as coisas. (Freitas, 2003, p. 67)

Haveria, ainda, outras propostas de organização de ciclos, algumas delas identificadas como mera proposta de "progressão continuada", mais preocupadas com a correção das estatísticas de fluxo escolar, mantendo uma aparente estrutura de ciclos, como é freqüentemente criticada a proposta da Secretaria de Educação do Estado de São Paulo. Constata-se na literatura aqui discutida uma reiterada preocupação em distinguir essas últimas propostas de outras que também defendem a organização escolar em ciclos de formação. Freitas (2003, p. 73-76) apresenta um amplo quadro comparativo das propostas, identificando as de progressão continuada como um "projeto histórico conservador de otimização da escola atual, imediatista e que visa ao alinhamento da escola às necessidades da reestruturação produtiva”. Já a escola de ciclos é reconhecida como um "projeto histórico transformador das bases de organização da escola e da sociedade, de médio e longo prazo, que atua como resistência e fator de conscientização, articulado aos movimentos sociais" (p. 73).

A necessidade de distinguir essas propostas é ainda mais premente quando se trata de discutir a sua implantação como proposta oficial para 
Sobre tempos e espaços da escola: do princípio do conhecimento...

toda uma rede de ensino. É interessante observar que um autor como Philippe Perrenoud, cujas concepções têm referendado propostas reformistas em vários lugares do mundo, em um artigo publicado no Brasil em 1999, mostrou-se cauteloso com relação à adoção sistemática da escola de ciclos, ao afirmar que até então nenhum sistema educacional de língua francesa havia adotado a organização escolar "sem séries, que promova apenas ciclos de aprendizagem", revelando seus grandes temores com relação à implantação de uma reforma com essas características: "Não somos capazes, ainda, de fazê-los funcionar promovendo uma ruptura clara e definitiva (...)" (Perrenoud, 1999, p. 8). Em obra mais recente sobre o assunto $(2004$, p. 26), esse autor lembra que, apesar de os ciclos terem sido introduzidos na França já em 1989, essa proposta não foi levada "até o fim". Também na Bélgica, no Quebec e em vários cantões suíços foram introduzidos "ciclos de dois anos, às vezes de maneira precipitada, sem bases conceituais sólidas e sem um grande questionamento sobre o sentido dessa inovação, provavelmente porque a reforma do currículo os preocupava mais”. Para tratar das reformas orientadas para os ciclos de aprendizagem, ele distingue três tipos de reformas educacionais: as de primeiro tipo transformam as estruturas escolares; as de segundo tipo, os currículos; e as de terceiro tipo, as verdadeiramente importantes, são aquelas que se dirigem "aberta e institucionalmente para o cotidiano dos alunos e professores nas classes e nas escolas" (1999, p. 11).

Não nos enganemos, a introdução dos ciclos de aprendizagem é uma reforma de terceiro tipo, ainda que aparentemente ela se apresente como uma reforma de estrutura e de currículo. No final da contas, são as práticas profissionais que é preciso transformar. Os valores, as atitudes, as representações, os conteúdos, as competências, a identidade e os projetos de cada um são, portanto, decisivos. Trata-se daquilo que os tecnocratas chamam de "fator humano", que passa pela formação (Perrenoud, 1999, p. 11).

Também Freitas (2003, p. 70) revela sua preocupação com a implantação sistemática de organização das escolas por intermédio dos ciclos: "Em nossa opinião, os ciclos não devem ser implantados como política pública que determine em massa sua adoção. (...) Não se deve fazer experimentos em redes inteiras". Ante essa prudente advertência de Freitas e lembrando as imensas dificuldades de implantação da educação seriada na escola brasileira (e não na escola européia, lembrando os cuidados de Perrenoud), deve-se acrescentar o imenso risco de que, 
ao final de todo um processo, não se distingam as decorrências e implicações dos dois modelos de reforma contrapostos (progressão continuada e ciclos), em que pesem as intenções e os esforços de seus articuladores. $\mathrm{O}$ que haveria de comum nos dois projetos? Provavelmente o caráter reformista da proposta, a despeito de todos os limites estruturais que tal perspectiva inexoravelmente contém, seja ela de caráter liberal ou socialdemocrata.

$\mathrm{Na}$ maioria dos autores consultados verifica-se uma propensão a promover mudanças na organização e na cultura da escola, sem alterar seus condicionantes estruturais. Neste sentido é importante lembrar um ponto freqüentemente ignorado quando se trata de reformular a escola e propor uma redefinição dos tempos e espaços escolares, o que também é proposto por Freitas (2003): a escola de tempo integral. Ora, se a questão é prover o estudante de mais tempo - de tempo para a sua permanência na escola, de tempo assistido, de tempo de convivência, de tempo para sua aprendizagem -, uma medida necessária não seria aumentar o tempo dele na escola? Falar em mudar o tempo da escola no sentido de sua democratização sem ampliar esse tempo não seria um grande contra-senso?

A grande aposta da reforma da escola organizada por intermédio dos ciclos incide sobre a mudança da cultura de alunos, professores, gestores e pais dos alunos. Seria fazer que se realize a reforma de terceiro tipo citada por Perrenoud, aquela que implica mudanças estruturais, de currículo e, sobretudo, do cotidiano de alunos e professores. Deve ser por esse motivo que grande parte das publicações sobre os ciclos de formação está orientada para promover o convencimento e a adesão dos professores à reforma. Os argumentos que sustentam esse exercício de convencimento já foram de certa maneira abordados aqui e não diferem da maioria dos que são utilizados para promover outras modalidades de reforma: a crítica aos processos de avaliação; a prevalência do "novo" sobre a tradição; a emergência de uma nova noção de temporalidade; a prevalência da aprendizagem sobre o ensino; a submissão ou completa anulação da teoria diante da prática; a ênfase na ação, na atividade e na experiência imediata como instância formadora; além de uma forte referência à psicologia para dar conta dos processos de desenvolvimento do indivíduo.

Pode-se afirmar que a organização escolar em ciclos propõe uma alteração de fundo no modo de conceber a escola: deixa de orientar-se por uma lógica vinculada aos processos de aquisição do conhecimento 
Sobre tempos e espaços da escola: do princípio do conhecimento...

(princípio do conhecimento) para orientar-se por uma outra lógica que, na falta de um nome melhor, está sendo chamada neste artigo de princípio da socialidade, o qual propõe que a escola deva ser uma instância cuja finalidade precípua seja promover a socialidade dos alunos, ou seja, efetiva-se como um espaço/tempo ao qual devam pertencer, constituir um lugar no mundo, deixando como secundária a tarefa de instruí-los para o mundo. O termo "socialidade" demarca, assim, um espaço/tempo de convivência representado pela escola.

Dessa forma, a mudança na maneira de conceber o tempo e o espaço é uma característica muito importante da reforma educacional em curso. É interessante pensar que a escola "tradicional" também investe na ampliação do tempo de escolarização (e conseqüentemente do espaço) quando acredita que, apesar de todos os problemas que isso possa acarretar, a reprovação do aluno possa dar a ele mais tempo para recomeçar e aprender. E também o faz a partir de uma leitura psicológica do processo de desenvolvimento e aprendizagem: reprovar é dar tempo para o aluno amadurecer, desenvolver-se, exercitar-se, na convivência com colegas que estão em níveis próximos dos seus. Como seu princípio é orientado pelo conhecimento, aposta na ordenação de dificuldades dos conteúdos e acredita que é "devagar que se vai ao longe" e, assim, "não se pode queimar etapas”. Os problemas que decorrem dessa concepção já foram exaustivamente abordados pela literatura e não serão retomados aqui, bastando lembrar que, como as condições para o pleno desenvolvimento dos processos de ensino-aprendizagem não se efetivam quando se trata da educação das massas, pois não há como incluir todos, são produzidos mecanismos cruéis de exclusão e discriminação dos alunos das classes trabalhadoras. Como se não bastasse, esse modelo exauriu até mesmo a disposição dos governos em continuar mantendo essa situação, sendo que, de duas décadas para cá, as agências multinacionais que engendram políticas educacionais em todo o mundo não se cansam de reclamar do dispêndio de recursos que representa sustentar o lento fluxo dos alunos da rede pública. Além disso, não nos esqueçamos, o mundo de hoje é muito diferente daquele em que essa escola foi pensada e já não se pode perder tempo, porque, afinal, tempo também é dinheiro.

A concepção de uma escola organizada em ciclos, por sua vez, modifica a noção de tempo na escola de forma inversa: não há formalmente um ganho no quantum de tempo em que o aluno irá permanecer na escola, pois, ao final, o período de escolarização será o mesmo. O que muda é 
que ele não terá um limite de tempo para avançar de uma etapa a outra, pois está livre das barreiras do princípio do conhecimento. Se o aluno não é retido ou excluído pela reprovação nas séries escolares, ele poderá permanecer na escola para usufruir o que essa escola pode lhe oferecer. $\mathrm{O}$ princípio é, portanto, da socialidade, da oportunidade de compartilhar a experiência da escola, de viver o tempo da escola, de conviver com outras crianças e adolescentes próximos de sua idade. Assim, diferente do que se diz sobre a organização escolar em ciclos, talvez a maior transformação resida no ganho de um espaço, ou de legitimidade e efetividade de acesso a esse espaço: permanecer na escola e ali usufruir tudo que ela pode oferecer. E o que essa escola tem a oferecer? A princípio, e isso não é pouco, o direito de permanecer na escola. Mas em que condiçóes esse direito é exercido? Retorna-se, então, à questão dos condicionantes estruturais que impedem que a escola se efetive como instância formadora, agora já dispensada das exigências do princípio do conhecimento. Mantém-se o aluno na escola de massas, investe-se em sua socialização e em seu desenvolvimento individual: mas não haveria de pretender mais?

De imediato, essa política tem o efeito de produzir um alívio nas taxas oficiais de fluxo escolar. Há, ainda, de se aguardar os efeitos de um complicador que virá a seguir sob a forma de avaliação institucional: as mesmas agências que exigem correção do fluxo a qualquer preço instauram procedimentos de avaliação que irão "corrigir as distorções do sistema", propondo mecanismos ainda mais sofisticados e eficientes de discriminação e exclusão dos que escaparam do princípio do conhecimento (e de seu viés excludente) lá na escola, mas terão de se defrontar com ele quando for a hora de se instalar no tempo e no espaço em sua vida adulta pessoal e profissional.

Essas mudanças conceituais estariam na base das justificativas das reformas por que passa a educação, incluindo especialmente aquelas voltadas para as mudanças do cotidiano de alunos e professores ou, como afirma Popkewitz (2001), para o "controle da alma". Expressam um conjunto de supostos que constituem uma racionalidade que vem calçar, justificar, amparar, sustentar as reformas educacionais (Miranda, 1997). Mais do que efetivamente transformar a educação, talvez esteja em causa mudar a maneira de compreendê-la, principalmente por parte daqueles que a realizam "na prática".

Por que é mesmo que a escola deve passar a se organizar por ciclos? A resposta a esta pergunta não foi ainda suficientemente tratada e mere- 
Sobre tempos e espaços da escola: do princípio do conhecimento...

ce ser mais bem discutida. Também não se trata de concordar com o argumento de Perrenoud (2004) na introdução de seu livro dedicado ao assunto: "Uma vez que os ciclos já existem". Seria, em contrapartida, próprio das inovaçóes que elas se imponham para serem assimiladas e debatidas depois? Ou é a urgência da prática que subtrai a reflexão? A prudência sugere que bem melhor teria sido que o debate ocorresse antes da implantação das propostas de ciclos nas redes de ensino brasileiras. $\mathrm{O}$ debate poderia contribuir para pôr em causa princípios distintos que presidem a adoção de um modo ou outro de pensar a escola. Isso pode não mudar o rumo das coisas, mas pode - e o que mais nos resta? - ajudar a compreender o rumo das coisas.

Recebido em julho de 2004 e aprovado em dezembro de 2004.

Referências bibliográficas

ADORNO, T.W. Educação e emancipação. Rio de Janeiro: Paz \& Terra, 1995.

ARENDT, H. Entre o passado e o futuro. São Paulo: Perspectiva, 1979. ARROYO, M. Ciclos de desenvolvimento humano e formação de educadores. Educação \& Sociedade, Campinas, v. 20, n. 68, p. 143-161, dez. 1999.

ARROYO, M. Ofício de mestre: imagens e auto-imagens. Petrópolis: Vozes, 2000.

CICLO. In: FERREIRA, A.B.H. Novo Dicionário Aurélio. Rio de Janeiro: Nova Fronteira, [s.d.] p. 323.

FREITAS, L.C. Ciclos, seriação e avaliação: confronto de lógicas. São Paulo: Cortez, 2003.

KRUG, A. Ciclos de formação: uma proposta transformadora. Porto Alegre: Mediação, 2002.

LAGEVIN, P.; WALLON, H. Le Plan Langevin-Wallon. Disponível em: <file://Macintosh HD/Desktop Folder/cidem/html/th...ucation/ edu_infos/textes_reference/edu_t010b.html >. [14/12/2000]. Acesso em: 9 mar. 2004. 
LIMA, E.S. Ciclos de formação: uma reorganização do tempo escolar. São Paulo: Sobradinho 107, 2002.

MIRANDA, M.G. Novo paradigma do conhecimento e políticas educacionais na América Latina. Cadernos de Pesquisa, São Paulo, n. 100, p. 49-56, mar. 1997.

PERRENOUD, P. Profissionalização do professor e desenvolvimento de ciclos de aprendizagem. Cadernos de Pesquisa, São Paulo, n. 108, p. 726, nov. 1999.

PERRENOUD, P. Os ciclos de aprendizagem: um caminho para combater o fracasso escolar. Porto Alegre: Artmed, 2004.

POPKEWITZ, T.S. Lutando em defesa da alma. Porto Alegre: Artmed, 2001.

VIGOTSKI, L.S. Obras escogidas: psicologia infantil. Madrid: Visor, 1996. t. 4. 